\title{
Ozone therapy in multiple disabled children
}

\author{
Rajeshwari Buch \\ BAMS Gujarat Ayurveda University. India.
}

ABSTRACT

OOPEN ACCESS

\section{Citation}

Buch R. Ozone therapy in multiple disabled children [abstract]. Proceedings of the 5Th WFOT Meeting; 2016 Nov 18-20; Mumbai, India. J Ozone Ther. 2018;2(2). doi: 10.7203/ jo3t.2.2.2018.11151

\section{Academic Editor}

Jose Baeza-Noci, School of Medicine, Valencia University, SPAIN

\section{Editor}

World Federation of Ozone Therapy, Bolgna, ITALY

\section{Received}

December 9, 2017

\section{Accepted}

December 10, 2017

\section{Published}

March 4, 2018

\section{Intellectual Property}

Rajeshwari Buch. This is an open access article distributed under the terms of the Creative Commons Attribution License (CC BY 4.0), which permits unrestricted use, distribution, and reproduction in any medium, provided the original author and source are credited.

\footnotetext{
Author Information

dr.rajeshwari0807@gmail.com
}

Multiple disabilities is term for child with several disabilities sensory associated with motor disabilities. Growing number of children are presented with development issues caused by cerebral palsy, autism, learning disabilities, ADHD, Genetic disorder, global delayed development. Problem of this children are multifold and affects the daily life of whole family. No such conventional treatment can cure these problems. They are treating specific symptoms of Autism and global delay improve the child functioning and helping them in daily activity. It is ethically correct to take advantage of ozone therapy when the best orthodox treatment has failed.

Anecdotal study was done in 47 children ranging from 8 months to 12 years of age with multiple disabilities. Along with conventional treatment and various therapy like occupational therapy, physio therapy, sensory integration, speech therapy, ozone therapy i.e rectal insufflation (10 mcg to $80 \mathrm{mcg}$ per $\mathrm{kg}$ ) ear insufflation ( $10 \mathrm{mcg} / 120 \mathrm{ml}$ for 5 to 10 minutes ) were given. In selected cases S/C injection, vacuum massage, matra basti with Ayurvedic medicated ghrut like "Bhrami Ghruth, Ashwagandha Ghruth, Mahakalyank Ghruth". The rectal insufflation of ozone is a systemic routed which dissolves quickly in the luminal contents of the bowel, where mucoprotiens and other secretory products with antioxidants activity readily react with ozone to produce reactive oxygen species (ROS) and lipid peroxidation products. These compound penetrate the muscular mucosa and enter the circulation of venous and lymphatic capillaries. This noninvasive technique can be used without risk in pediatric and elderly patients. Ear insufflation through capillaries of ear: it is believed that it is absorbed, it secretes hormone endorphin which gives cool \& calm effect which improves the quality of sleep. Vacuum increases the blood flow and ozone can react better and S/C injection improves local blood circulation. Herbal drugs like centella acitica (Brahmi) shows significant improvement in neuron function in areas of the brain associated with learning and memory useful in ADHD. "Withenia Somnifera (Ashwagandh)" shows high affinity for GABA receptors that is helpful in memory loss, anxiety and ADHD. "Ghrut" is a detoxifying agent makes the organ soft increases intelligence refine the intellect (dhi), improve the memory (Smruti), increases digestive AGNI, cools the body and gives synergistic effect with ozone application (Yogwahi).

\section{OBSERVATION :}

1. Improvement in Alertness, immunity, Digestion

2. Weight Gain

3. Improvement in muscle tone that enables child to perform daily physical activity 